\title{
Üç Hikâye Üç Varoluş Biçimi: \\ Cemil Kavukçu'da Ben/Öteki ve Toplum
}

\author{
ARŞ. GÖR. EMEL ARAS*
}

Öz

1980 sonrası Türk öykücülüğünün önemli isimlerinden Cemil Kavukçu, hikâyelerini inşa ederken genellikle gündelik problemlere odaklanır. Gündelik problemlerin etrafında şekillenen bu hikâyelerin bir kısmı anlam alanlarını genişletmeye müsait yapıdadırlar. “Düşkaçıran” isimli öykü kitabının "Kalan” bölümünü oluşturan ilk üç hikâye de benzer bir özellik göstermekte ve ele aldığı sıradan meselelerin çerçevesini yoruma açık felsefi derinliği ile birlikte genişletmektedir. "İki Nokta Üst Üste", "Doç" ve "İkizler" ismini taşıyan bu üç hikâyenin çokluktan tekliğe, toplumdan benliğe doğru ilerleyen bir çizgisi söz konusudur.

Her üç hikâyenin de merkezinde yer alan Fatih karakterinin yaşadığı dönüşüm ve bu dönüşüm sürecinde ortaya çıkan ben, öteki ve toplum çatışması çalışmamızın ana eksenini oluşturacaktır. Süreç içerisinde gelinen yalnızlaşma durumu, Ortega y Gasset'nin İnsan ve Herkes adlı eserinde ortaya koyduğu argümanlar ile zaman ve mekân olguları etrafinda değerlendirilecektir.

Anahtar sözcükler: Cemil Kavukçu, Düşkaçıran, İnsan ve Herkes, Ben, Öteki, Toplum

\section{THREE STORIES THREE FORMS OF EXISTENCE: SELF/OTHER AND SOCIETY IN CEMILL KAVUKÇU}

\section{Abstract}

Cemil Kavukçu, one of the most important names of Turkish storytelling after 1980, generally focuses on the daily problems while establishing his stories. Some parts of the stories shaped around daily routines are suitable for expanding their meaning areas. The first three stories that constitute the chapter "Kalan" of the book "Düşkaçıran" show a similar feature and widen the framework of ordinary issues they deal with, with the philosophical depth that is open to interpretation. There is a line which moves from plural to single, from society to self in the stories of "İki Nokta Üst Üste", "Doç", "İkizler". This study will be focused on the transformation process of Fatih who is the main character of all three stories and the conflict of self, other and society which reveals in this transformation process. The state of isolation in the process will be evaluated around the time and space phenomena with the arguments of Ortega y Gasset in his book Man and People.

\footnotetext{
* Düzce Üniversitesi Türk Dili ve Edebiyatı Bölümü, emelaras@duzce.edu.tr, orcid.org/ 0000-0001-2345-6789 Gönderim tarihi: 29.10.2018

Kabul tarihi: 02.12.2018
} 
Keywords: Cemil Kavukçu, Düşkaçıran, Man and People, Self, Other, Society

\section{GİRIŞ}

Tazın dünyasına 1980 sonrası çeşitli dergilerde yayımladığı öykülerle dâhil olan Cemil Kavukçu, öykülerinde genellikle sıradan insanların yaşamlarına

_Ldaklanır. Bu odaklanma hâliyle sıradanlığı aşma imkânı ise eserlerin taşıdığı felsefi değeri yakalamakla mümkün gözükmektedir. Bu çalışma vasıtasıyla "Düşkaçıran" adlı öykü kitabında yer alan "İki Nokta Üst Üste", "Doç" ve "İkizler" başlıklı eserlerin birbiriyle olan ilişkisi bağlamında taşıdıkları felsefi değer de bu noktada önem arz etmektedir.

Bu üç öyküde takip edilen toplumsallıktan bireyselliğe dönüşüm süreci, 1980 ve sonrası Türk öykücülügün genel eğilimidir. Toplumcu gerçekçiliğin rehber edildiği 1950 sonrası öykü anlayışını takip eden bu bireyselleşme süreci, toplumun gerçeklerinden kopuk eserler verilmesi nedeniyle eleştirilmiştir.

"1980, 1990 kuşağ 1 için getirilen en önemli eleştiri, toplumsallıktan uzaklaşıp bireyciliğe yönelmeleri olmuştur. Kimi etkin eleştirmenler, 1980 ve 1990 kuşağını toplumsal sorunlara ilgisiz, bireyci, bunalımcı olarak niteleyip insansız öykü yazıldığını, herkesin kendi benini anlattığı eleştirilerinde bulundular. Bu da içe kapanık, dış dünyanın gerçeklerinden kopuk bir edebiyat tutumu demekti" (Tosun, 2014, s. 56).

Her ne kadar dönem koşulları içerisinde eleştirilse de bu süreç, kendisinden sonra daha belirgin bir şekilde açığa çıkan modern ve postmodern yazın türlerinin hazırlayıcısı olması bağlamında önemlidir. Modern bireyin içerisinde yaşadığı toplumdan ve toplumsal normlardan kopuş süreci "İki Nokta Üst Üste" adlı eserin ana karakterleri Fatih ve Ceyda üzerinden takip edilebilir. Ayrılmanın eşiğinde olan bu çift, son kez bir araya gelerek yollarını ayırmak üzere görüşeceklerdir. Fakat Ceyda bu kararı kendisinin dile getireceğini düşünürken Fatih Rusya'ya gideceğini açıklayarak ayrılık kararını dolaylı olarak bildirmiş olur. Kendinden emin bir şekilde buluşma noktasına gelen Ceyda, Fatih'in yaptığı bu açıklama ile sarsılır. Oysa o, Ömer adında başka birisiyle bir süredir görüşmektedir ve ayrılık konusunda da oldukça kararlıdır. Fakat Fatih'in hemen yarın Rusya'ya gitmek üzere yola çıkacağını açıklaması Ceyda'nın özgüvenini yerle bir eder. İki gencin ayrılık sahnesine odaklanan ve ayrılık kararının açılanmasıyla son bulan bu hikâye, "düz hikâye" olarak değerlendirilebilir. Fakat arkasından gelen "Doç" ve "İkizler" isimli öyküler ile bu ilk hikâyenin giriş niteliğinde olduğu anlaşılmaktadır.

"Doç" isimli öyküde ise işlerden, koşuşturmacadan, ilişkilerden yorulmuş bir adamın hikâyesi anlatılmaktadır. Bu adam, ilk öykünün kahramanı Fatih'ten başkası değildir. Fatih, Ceyda'ya Rusya'ya gideceğini söylemiş; fakat aslında sadece bulunduğu ortamdan ve tüm 
ilişkilerden kopmak amacıyla mekân değiştirme yoluna gitmiştir. Yeni yaşamaya başladığı eve girip çıkarken kapının önünde sürekli bekleyen "Doç" isimli bir köpek Fatih'in tek arkadaşı hâline gelmiş ve onu yalnızlığına ortak etmek üzere evine almıştır. Fatih, insanlarla istediği biçimde kuramadığı ilişkiyi "Doç" ile kurmak istemiştir. Onun geçmiş yaşamına dair her şeyi geride bırakma arzusu internet kullanımından uzaklaşmasını da kapsamaktadır. Öyle ki Fatih ancak bir internet

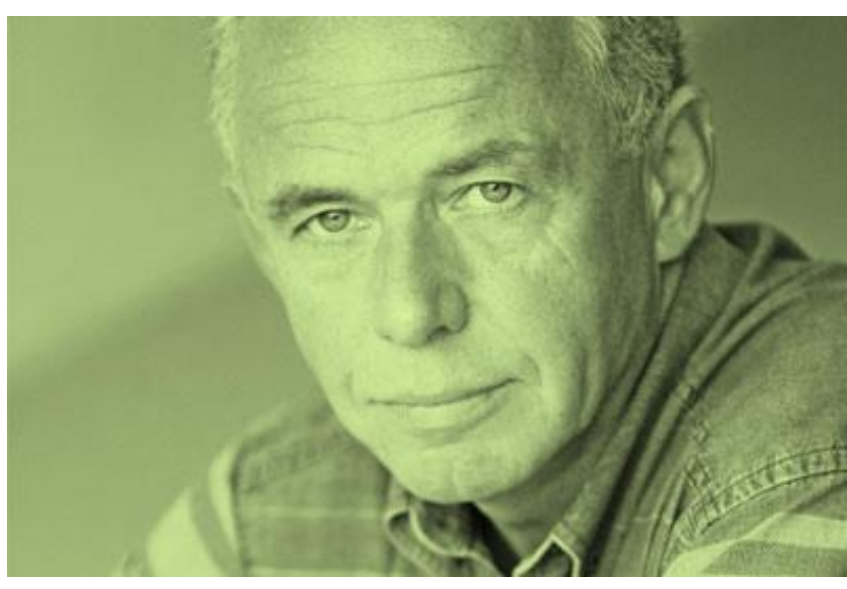
kafeye gidip geçmiş yaşamına dair neler olup bittiğini merak ettiğinde Ceyda'dan gelen elektronik postayı görür. Ceyda, Fatih ile dost kalmak istediğini yazmıştır, fakat Fatih ona bunun mümkün olmadığını ve kendisinin Doç isimli bir dostunun olduğunu yazar. İkinci hikâyenin genel çerçevesi de bu eksendedir. Üçüncü ve çalışmamızın son öyküsü olan "İkizler" isimli öykü, evde tek başına kitabını okuyan Fatih'in davetsiz misafirleri ile yaşadıkları üzerine kurgulanmıştır. Çatı tamiri için geldiklerini söyleyen ikizler, hemen çalışmaya başlarlar. Fatih'in yalnız yaşamına oldukça hızlı bir şekilde dâhil olan bu ikili, evin içinde rahatça dolaşır, öyle ki biri Fatih'in şapkasını izinsiz kullanır, bir diğeri Fatih'ten izin almaksızın odasına girerek telefonunu şarja takar. Bu gibi davranışlar Fatih'i rahatsız etse de tam manasıyla sınırlarını zorlamaz. Fakat en sonunda ikizlerden birinin Doç'un kuyruğuna basması ve onun canını yakması Fatih için son noktadır. Bu olay üzerine Fatih, ikizleri evinden kovar. Sonrasında ise ev sahibi Güven Bey Fatih'i arayarak, yarın için çatıyı tamir etmek üzere üç kişinin geleceğini belirtir. Güven Bey'in ikizler hakkında hiçbir fikri yoktur. $\mathrm{Bu}$ sahne ile birlikte, Fatih ve ikizler arasında yaşananların gerçek olmadığı anlaşılmakta, yaşananlar hayal ürünüymüş gibi gözükmektedir.

Fatih isimli karakterin toplumsal yaşamdan bireysel yaşama geçişini adım adım anlatan bu üç öykü, "kişisel bir geri çekilme"nin nedenleri ve sonuçları bağlamında okunabilir. Ceyda ile kurduğu ilişkinin anlamsızlaştığı noktada ilişkiyi bitirme ve bulunduğu mekânı terk etme yoluna giden Fatih'in durumu, Ortega y Gasset'nin ortaya koyduğu ben ve Öteki ilişkisi bağlamında ele alınabilir:

"İnsanın doğumundan başlayarak, dolayısıyla her zaman Öteki'ne açık olduğu, tüm yapıp ettiklerinde kendinden ayrı ve yabancı bir varlık olarak Öteki ile hesaplaşma durumunda olduğu söylendiğinde, o açıklığın Öteki'nden yana mı yoksa karşıt $\mathrm{m}$ olduğu belirtilmiyor. Ötekine yönelişin iyi ya da kötü niyetle olmasından daha önce gelen bir şey bu. Ötekini soymak ya da öldürmek de, tıpkı onu öpmek ve özveride bulunmak gibi, ilkin ona açık olmayı gerektirir" (Gasset, 2014, s. 107). 


\section{CEMIL KAVUKÇU}

\section{DÜŞKAÇIRAN}

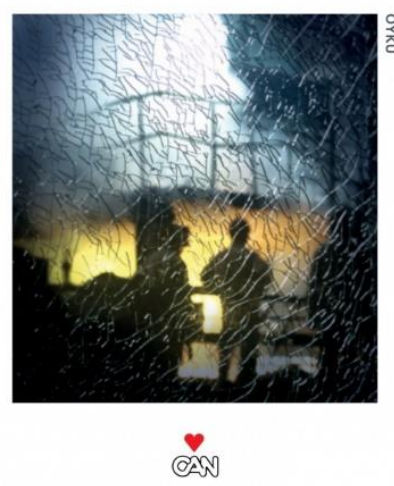

Fatih'in de Ceyda ile bir süre ilişkisini sürdürüp sonlandırma noktasına getirmesi, "benlik"inin "öteki"ne açı olduğunu, dolayısıyla toplumsal yaşama açık olduğunun göstergesidir. Fakat Ceyda ile yaşadığı ayrılıktan sonra Fatih, tıpkı Gasset'nin Batı insanının "dünyasız" kaldığına ilişkin beyanında olduğu gibi solipsizme düşme tehlikesini içinde taşır.

"Hayır, yaşam salt benim zihnimin, benim fikirlerimin varolması değildir: tam tersidir. Descartes'tan bu yana, Batı insanı dünyasız kalmıştı. Ama yaşamak demek, yaşamın benim dışımda olması zorunluluğu demektir, ortam ya da dünya denen o mutlak dışta: İstesem de istemesem de o dünyayı bütünleyen şeylerle, minerallerle, bitkilerle, hayvanlarla, diğer insanlarla, zorunlu olarak hiç durmadan yüzleşmem ve çarpışmam demektir. " (Gasset, 2014, s. 59)

İnsanın kendi dışındaki varlıklarla bir şekilde yüzleşmek ve çarpışmak zorunda olması, Fatih'in Doç ile kurduğu ilişkinin gerekçesi olarak görülebilir. Fatih, her ne kadar yaşadığı mekânı ve onu dolduran insani çevreyi terk etse de yalnız yaşamına attığı ilk adım bir süre sonra onun bir köpekle ortak bir yaşam kurma noktasına getirmiştir. Aynı şekilde "İkizler" isimli öyküdeki ikizlerle girilen zorunlu ilişki de bu duruma örnek olarak gösterilebilir. Fatih'in kendi çevresini saran tüm insanlardan ve nesnelerden kopma arzusunun gerçekleşebilme ihtimalinin zayıflığı da bu noktada ortaya çıkar. İnsan, nefes aldığı süre zarfınca dış dünya ile bir şekilde ilişkiye açık olmalıdır. Özellikle Doç ile birlikte bir yaşam kurmaya çalışan Fatih'in bu çabası da Gasset açısından anlamlı gözükmemektedir. Zira Gasset, insan dışındaki varlıklarla sınırlı bir ilişki kurulabileceğini ifade ederken, "biz"lik noktasında bir ilişkinin ancak insanla mümkün olduğuna işaret eder:

"Taş ile bizlik olmaz. Hayvanla da pek sınırlı, bulanık ve sorunsal bir bizlik olur ancak. " (Gasset, 2014, s. 110).

Yine de Fatih'in yaşamını insanlardan uzak bir şekilde inşa edebilmeyi kısa süreli de olsa başarabilmesi insan yaşamının "yalnızlık"la kurduğu ilişkinin anlaşılması adına önem arz eder. Çünkü insan, özünde yalnız bir varlıktır ve Fatih de bu öze dönme noktasında önemli bir adım atmıştır.

". . . insan yaşamı, dar anlamıyla başkasına aktarılamaz olmasından ötürü

yalnızlk'tır, kökten yalnızlı. " (Gasset, 2014, s. 58)

Yalnızlığın kutsanması durumu, bir noktaya kadar Fatih'in tercihleriyle ilerleyen bir süreç olarak anlaşılabilir. Fakat üçüncü hikâyede yer alan ikizler karakterlerinin Fatih'in yalnızlığına yönelik bir tehdit oluşturması ve özel yaşamına izinsiz müdahalelerde bulunmaları bir yönüyle yalnızlığın imkânsızlığına da işaret etmektedir. İçinde bulunduğumuz yüzyılda kişisel yönelimlerimizin nasıl bir yaşamı tercih ettiğimiz 
noktasında yetersiz olduğu, insan yaşamının birden fazla yönlendirici unsur tarafından yönetildiği gerçeğini de açığa çıkarmaktadır. İkizler karakterleri, öykü içerisinde gerçek anlamda var olan karakterler olmasa dahi, insanın bilinçaltında diğer insanların kendi yaşamına müdahale edeceği yönünde bir düşüncesi olduğunu göstermesi açısından önemlidir. Böylesi bir tehlike durumu, modern dünyada her an kendisini var eder.

Öykülerin ana karakteri olan Fatih'in yalnızlığa doğru ilerleyen yaşam yolculuğu zaman ve mekân olgularıyla da sıkı sıkıya ilişkilidir. Bu nedenle zaman ve mekân hususları ayrı ayrı başlıklar altında ele alınarak Fatih'in toplumsallıktan bireyselliğe doğru ilerleyen sürecinin daha etraflıca anlaşılması amaçlanmaktadır.

\section{ZAMAN}

Hikâyenin temel unsurlarından olan zamanın durumu, ilk öykü ve son öykünün kendi iç akışının hızı bağlamında düşünülebilir. Fatih'in uzaklaşmak istediği yaşantının zamanı son derece hızlıdır ve bu yaşantı içerisinde dönüp kendisine bakabilecek, kendi yaşamını anlamlandırabilecek bir zaman dilimini bulabilmesi dahi mümkün değildir. Bu nedenle Fatih bu hızlı yaşam içerisinde yalnızca kendine dönebileceği bir zaman dilimi yaratabilmek adına Ceyda ile olan ilişkisini noktalayarak bulunduğu mekânı değiştirmiş ve peşinden gelen iki öykünün zamanı da bu karar ile birlikte yavaşlamıştır. "İki Nokta Üst Üste" adlı bu öyküyü takip eden ikinci öykü "Doç"ta öykü zamanı yavaşlar ve Fatih'in eve girip çıkarken gördüğü köpek "Doç" bir nevi onun zamanının ölçüsü hâline gelir. Fatih günlerden, aylardan ya da saatten söz etmeksizin eve girip çıkarken "Doç"un kapının önünde olup olmadığına odaklanır. Zamanın yavaşlaması Fatih açısından çok önemli bir sorundur. Öyle ki bu durum, öykü içerisinde de açıkça dile getirilir:

"Zamanı olabildiğince yavaşlatmalıydı. Aradığı huzuru böyle bulabilirdi" (Kavukçu, 2012, s. 25).

Fatih'in zamana ilişkin gözlemleri, yaşamın karmaşasıyla paralellik gösterir. Yaşamın bizi her alanda kuşatan karmaşası, birçok uyarıcıya aynı anda açık hâle getirerek odak noktamızı çeşitlendirmesi de zamanın hızının artışıyla ilişkilidir. Bulunduğu yeri terk ederek yazlık bir siteye yerleşen Fatih, hız mevzuuna dair düşüncelerini anlatırken yaşadığı tatil sitesinin monoton döngüsünde yer alan eylemleri sıralar: 
"Sabahin erken bir saati sayılmaz ama tatil sitesinde yaşam belirtisi yok gibi. Nasıl olsun ki? Kısacık yaz geceleri, uzun süren mangal partileri, rakı muhabbetleri, şen kahkahalar, kimi balkonlardan duyulan okey taşı şıkırtıları, kıyı boyunca, dondurma külahlarını meşale gibi tutup yürüyüşe çıkmış kalabalık aileler, bebek arabalarında çoktan uykuya geçmiş minikler, sürekli bir şey isteyen sevgi dilencisi çocuklar, bisiklet akrobatı yeniyetmeler, gökyüzünü tarayan renkli ışık okları, kafeler, diskolar, birbirine karışan müzikler, oralarda filizlenen günlük ya da sezonluk aşklar. . ." (Kavukçu, 2012, s. 29)

Böylesi bir monotonluk hâli, eylemlerin birbirini takip edişindeki düzenliliğin gözle görünür bir berraklıkta oluşu, Fatih'in aradığı güven duygusunun tatmini açısından da önemlidir. Bu sözlerin devamında Fatih, bu döngüye dâhil olan insanlara dair şunları da söyler:

"Bütün kış bunun özlemiyle geçmiş, tatil iple çekilmiştir. Zaman alabildiğine sağılmalıdır. Sağılır da. Gecenin hakkı verilerek yorgun argın yatağa girilir, sıcağa ve sivrisineklere aldırmadan ter içinde öğleye dek uyunur" (Kavukçu, 2012, s. 29).

Esasen bu noktada, Fatih üzerinden modern insanın içine düştüğü girdaba uzaktan bir bakış atılır. Tüm yıl yalnızca tatil özlemiyle çalışan ve sonunda belli başlı eylemleri gerçekleştirerek arınma sağlamaya çalışan insan bu anları uzatmanın peşindedir.

Üçüncü öykü olan "İkizler"de ise artık Fatih'in yaşamında yalnızca Doç vardır ve zaman yönetimi konusunda özgürdür. Bu öyküde açığa çıkan tek problem, öyküye konu edilen ve gerçeklikleri konusunda şüphe uyandıran ikizler karakterlerinin Fatih'in yaşamına müdahale etmeleridir. Bu müdahale dolayısıyla Fatih, bilinçli bir tercihte bulunarak girdiği monoton yaşamın sekteye uğradığı görülür. İkizlerin evde çalıştı̆̆ı saatler ve günler Fatih açısından sonu gelmeyen bir işkenceye dönüşür ve zaman mefhumu her an genişleyen bir hâl alır.

\section{MEKÂN}

Zamanın dönüşümü, mekânın dönüşümü ile birlikte ele alınmalıdır. Zira, zamansal karmaşanın yarattığı hızdan uzaklaşmanın yolu, mekânsal kalabalıktan da uzaklaşmaktan geçer. Bu nedenle Fatih, "zamanı yavaşlatma" isteğini gerçekleştirmek üzere harekete geçerken öncelikle bulunduğu mekânı terk etme yoluna gider. Bu amaçla, gitmek üzere "yola çıkar". "Doç" öyküsünde Atilla İlhan'dan yapılan bir alıntı da bu ilişkinin açı̆̆a çıkarılması bağlamında önem arz eder: 
"Attilâ İlhan'ın şiirinde olduğu gibi, yola çıkınca gidilir, büyük aşklar çığlık çığlığa

terk edilirdi" (Kavukçu, 2012, s. 26).

"Gitme" düşüncesi mekânsal değişim arzusunu ortaya çıkaran temel dürtüdür. Fatih, sevgilisi Ceyda ile yaşadığı sorunlardan uzaklaşmak ve kendine dönmek üzere atacağı ilk adımı bu düşünce ile eyleme dönüşmüştür.

"Ama yine de özünde kendinden uzaklaştığını görmüştü. Değişmiyor, bozuluyordu. Çok sevdiği kentten sıkılmıştı. Onsuz yapamam dediği, kıskançlık krizlerine tutulduğu, uzaklaştığı için acılar çektiği kadın bir yıldız gibi kayıvermişti yaşamından. Yakıştırdığı özellikler pul pul üzerinden dökülürken herkes gibi bir kadın çıkmıştı karşısına. Onca acıyı çektiğine değmiş miydi? Yalnız onu değil, hayallerini de yitirmişti.

Yapacağ1 tek şey gitmekti. " (Kavukçu, 2012, s. 27).

Fatih içerisinde bulunduğu dünyanın kendi beklentilerini karşılamadığı noktada "gitme" düşüncesiyle hareket eder.

Önceleri, daha hareketli bir yaşamı varken Fatih, sürekli "mekân değiştiren" biri olduğunu beyan eder. Sürekli mekân değiştirmek de bir yönüyle zamanın akışına kapılan bireyin mekânın da akışına kapılması ile ilişkili bir durumdur.

"Olduğu yerde duramayan, sürekli mekân değiştiren, kabına sığmayan adama ne olmuştu? İşlerden, koşuşturmadan, ilişkilerden, temposu gittikçe artan zamanın içinde oradan oraya savrulmaktan yorulmuştu. " (Kavukçu, 2012, s. 25).

Dolayısıyla Fatih, "gitme" düşüncesiyle zamanı yavaşlatmak istemesinin yanı sıra sabit bir mekâna da ait olma arzusuyla hareket etmiştir. Bu düşünce önce onun içinde bulunduğu hareketli yaşamı terk etmesine, tek başına bir tatil kasabasında yaşamaya başlamasına neden olur.

\section{ANLAM SORUNU}

Fatih'in yalnızlaşma isteğinin altında yatan temel nedenlerden bir tanesi yaşamın anlamı noktasında ortaya çıkan boşluğu doldurma isteğidir. Bu hâliyle Fatih, yaşamın hızına kapılan metropollerde yaşayan insanların prototipi niteliğindedir. Fatih'in bu sorunu çözmek adına bulunduğu girişim, Doç ile kurduğu ilişki ile sembolleşir. İnsan kalabalıkları arasında aradığını bulamayan Fatih, bir köpeğin bakışlarında bu anlam sorununun çözüldüğünü düşünür.

"Birden onu hissetmiş, başını hafifçe sağa doğru döndürdüğünde yaşamın gizemini çözmüş bir köpeğin hüzünlü ve anlayan bakışlarıyla karşılaşmıştı"(Kavukçu, 2012, s. 27).

Doç'un kendisini anladığını düşünen Fatih, hayatın anlamını çözme başarısını birçok insanın göstermediği bir dünyada bunu bir köpeğin başardığına işaret ederek bizi bir kez 
daha düşünmeye sevk eder. Üstelik kendisinin yaşadığı yeri ve çevresini terk etmesinin temel nedeni de bu anlam sorunu, kendi yaşamını kontrol edebilme isteğidir.

"İkizler" öyküsündeki gerçeküstü durum da bu anlam sorunuyla ilişkili olabilir. Fatih'in zihninin kendilik problemiyle aşırı derecede meşgul olması, onun, âdeta, birtakım halisünasyonlar görmesine neden olmuştur. Kendi varlığını, kendi yaşamının anlamını sorgulamak üzere çıtı̆̆ı bu yolda ilişki kurduğu tek varlığın Doç olması ve ikizler gibi tek maharetleri Fatih'in yaşamına müdahale etmek olan iki kişi ile muhatap olduğunu hayal etmesi Fatih'in zihninin meşguliyetini açıkça ortaya koymaktadır.

\section{SONUÇ}

Cemil Kavukçu'nun "Düşkaçıran" adlı öykü kitabında yer alan "İki Nokta Üst Üste", "Doç" ve "İkizler" isimli öyküler bir karakterin gelişimi/dönüşümü bağlamında ele alınmıştır. Fatih isimli karakterin toplumsallıktan bireyselliğe doğru yaptığı hamleler, bir çeşit bilinçli yalnızlaşma şeklinde ortaya çıkmıştır. Bu yalnızlaşma karakterin bilinçli olarak mekân değişikliğine gitmesi ve zamanın akışını yavaşlatma isteğiyle birlikte ortaya çıkmıştır. Fatih, öncelikle içinde bulunduğu ilişkiler ağının dışına çıkma isteğini dile getirmiş, bu istekle birlikte mekânsal değişim yoluna gitmiştir. Söz konusu ilişkiler ağının Fatih'i kendi iradesi dışında bir zaman algısı ile yüz yüze bırakmasının da eserlerin merkezinde yer alan bireysellik dürtüsünü tetikleyen bir unsur olduğu tespit edilmiştir. Dolayısıyla, bireyin yalnızlaşma arzusu, mekân ve zamanın dönüşümü ile var olmuştur. Modern dünyanın insanı içerisine çektiği girdaptan sıyrılma arzusunun eyleme dönüşebilmesi, ancak bilinçli ve kararlı bir bireyin eylemselliği ile mümkündür. Fatih'in de bu bağlamda modern insanın prototipi niteliği olduğu sonucuna ulaşılmıştır.

\section{KAYNAKÇA}

Kavukçu, Cemil (2012). Düşkaçıran. İstanbul: Can Yayınları.

Gasset, Ortega (2014). İnsan ve Herkes. Çev. Neyire Gül Işık. İstanbul: Metis Yayınları

Tosun, Necip (2014). Modern Öykü Kuramı. Ankara: Hece Yayınları. 